\title{
ESTUDO DA APLICAÇÃO DO VAPEX EM RESERVATÓRIOS DE ÓLEO EXTRAPESADO
}

\author{
A. L. S. MOURA ${ }^{1}$, A. A. R. DINIZ ${ }^{1}$, J. L. M. BARILLAS ${ }^{1}$ \\ ${ }^{1}$ Universidade Federal do Rio Grande do Norte, Graduação em Engenharia de Petróleo \\ E-mail para contato: allene_moura@ hotmail.com, anthony_andrey@yahoo.com, \\ jennys@eq.ufrn.br
}

\begin{abstract}
RESUMO - Sabe-se que naturalmente só é possível recuperar uma pequena fração de óleo dos reservatórios, então com o intuito de aumentar o volume de óleo recuperado a indústria petrolífera sempre procura investir e desenvolver técnicas que aumentem essa produção. Existem os métodos convencionais e os métodos de recuperação especiais, que tem como principal finalidade retirar parte do óleo que não foi produzido utilizando o método convencional. Um dos processos indicados para ser aplicado em reservatórios de óleo pesado e extrapesado é o método miscível, em especial o VAPEX, que é caracterizado pela injeção de solvente vaporizado no reservatório. Este trabalho tem o intuito de analisar a recuperação de óleo de um reservatório com características do Nordeste Brasileiro utilizando o método VAPEX e avaliar o comportamento do método ao se alterar diferentes parâmetros operacionais como: tipo de solvente injetado, vazão de injeção e a distância vertical entre os poços injetor e produtor. $\mathrm{O}$ estudo foi realizado através do simulador GEM ("Generalized Equation-of-state Model Simulator"), do grupo CMG ("Computer Modelling Group").
\end{abstract}

\section{INTRODUÇÃO}

Devido às grandes quantidades de hidrocarbonetos retidas no reservatório após a exaustão da sua energia natural, a indústria petrolífera percebeu a necessidade de desenvolver técnicas para extrair uma maior quantidade de óleo. Além disso, grande parte de todo óleo existente no mundo apresenta uma viscosidade elevada, o que dificulta ainda mais sua produção. Vários métodos foram criados de acordo com a conveniência de cada reservatório, dependendo de cada método eles podem ser aplicados para elevar a pressão do reservatório, aumentar a produção em um menor tempo, facilitar o escoamento do óleo reduzindo a viscosidade e/ou a tensão interfacial do óleo ou até mesmo dar início a vida produtiva de um poço. Existem os métodos convencionais de recuperação, que têm como finalidade deslocar o óleo para fora dos poros da rocha, mas devido à alta viscosidade do óleo de alguns reservatórios nem sempre é eficiente e os métodos especiais que são mais complexos e atuam nesses reservatórios que possuem maior dificuldade de produzir.

Um dos métodos classificado como especial é o método miscível que se caracteriza pela ausência de interface entre os fluidos deslocante e deslocado, segundo Thomas (2004) a importância desse processo está relacionada com a sua habilidade em reduzir as forças capilares e interfaciais que, do contrário, causariam a retenção do óleo no reservatório. Os métodos miscíveis se ocupam da injeção de fluidos que venham a se tornar ou que sejam miscíveis com o óleo do reservatório, de tal modo que não existam tensões interfaciais. Dessa maneira, o óleo será deslocado para fora da área que for contatada pelo fluido injetado. 
Dentre os métodos de recuperação avançada pode se encontrar o processo VAPEX, processo que está em fase de desenvolvimento tecnológico, como alternativa aos processos de injeção de vapor. Esse método nos últimos anos vem sendo bastante visado devido a ausência do uso de vapor. O mecanismo deste processo consiste na injeção de solvente vaporizado de hidrocarboneto em reservatórios de óleo pesado e betume, utilizando dois poços horizontais em paralelo, um injetor, e um produtor, que está localizado abaixo do injetor. A pressão de injeção do solvente vaporizado é levemente menor ou igual à pressão de vapor de saturação. Ao redor e acima do reservatório é expandida uma câmara de vapor formada pelo solvente vaporizado ao ser injetado, promovendo uma redução nas tensões interfaciais e consequentemente melhorando a mobilidade do óleo. O solvente diluído ao entrar em contato com o óleo reduz a viscosidade do mesmo, facilitando seu deslocamento permitindo a drenagem por gravidade até o posso produtor. Nesse trabalho foi realizado um estudo da aplicação de um método miscível, o VAPEX, em um reservatório com características do nordeste brasileiro, onde dessa forma pôde-se comprovar o funcionamento do método e analisar a influência na produção do óleo a partir da variação de parâmetros como: vazão de injeção, distância vertical entre os poços e tipo de solvente. Essas análises foram realizadas comparando os resultados gráficos da produção acumulada, além de mapas da viscosidade ou densidade. Para a realização dessas análises, foram feitos simulações utilizando um modelo computacional. O simulador utilizado foi o GEM ("Generalized Equation-of-state Model Simulator”) do grupo CMG (“Computer Modelling Group”), versão 2012.10.

\section{METODOLOGIA}

Neste trabalho, a modelagem de fluido foi realizada utilizando características de um óleo da região do Nordeste Brasileiro, ajustado em sete pseudocomponentes. A Tabela 1 mostra a composição dos pseudocomponentes.

Tabela 1 - Agrupamento e percentual dos pseudocomponentes

\begin{tabular}{|c|c|}
\hline Componentes & Fração molar (\%) \\
\hline CO2 - N2 & 0,69 \\
\hline C - C9 & 10,00 \\
\hline IC4 - NC5 & 0,31 \\
\hline C6 - C19 & 17,41 \\
\hline C20 - C29 & 6,58 \\
\hline C30 - C39 & 25,00 \\
\hline C40+ & 40,00 \\
\hline
\end{tabular}

Foi estudado um modelo de reservatório homogêneo e com características do Nordeste Brasileiro. A Tabela 2 representa as propriedades e dimensões rocha-reservatório, como também o refinamento do reservatório.

Tabela 2. Características do reservatório

\begin{tabular}{|c|c|}
\hline Área do reservatório & $100 \times 300 \mathrm{~m}^{2}$ \\
\hline Espessura do reservatório & $30 \mathrm{~m}$ \\
\hline Número de blocos nas camadas $\mathrm{i}, \mathrm{j}, \mathrm{k}$ & $21,20,16$ \\
\hline
\end{tabular}




\begin{tabular}{|c|c|}
\hline Total de blocos & 6720 \\
\hline Comprimentos dos poços horizontais & $300 \mathrm{~m}$ \\
\hline Volume de óleo in place $^{\circ} \mathrm{C}$ & $94734 \mathrm{~m}^{3} \mathrm{std}$ \\
\hline Viscosidade do óleo @ T 38 ${ }^{\circ} \mathrm{C}$ & $10000 \mathrm{cp}$ \\
\hline Profundidade do reservatório & $200 \mathrm{~m}$ \\
\hline Permeabilidade horizontal (kh) & $1000 \mathrm{mD}$ \\
\hline Permeabilidade Vertical (kv) & $100 \mathrm{mD}$ \\
\hline Porosidade & $25 \%$ \\
\hline Saturação de água conata & $29 \%$ \\
\hline Temperatura & $38{ }^{\circ} \mathrm{C}$ \\
\hline Espessura da zona de óleo & $200 \mathrm{~m}$ \\
\hline Contato água-óleo & $220 \mathrm{~m}$ \\
\hline Pressão & $1979 \mathrm{kPa}$ \\
\hline Compressibilidade da formação & $4,3510^{5} 1 / \mathrm{kPa}$ \\
\hline
\end{tabular}

A Figura 1 apresenta uma vista 3D do reservatório, onde mostra a espessura de cada camada e as dimensões do reservatório, bem como os poços injetor e produtor.

Modelo do Reservatório

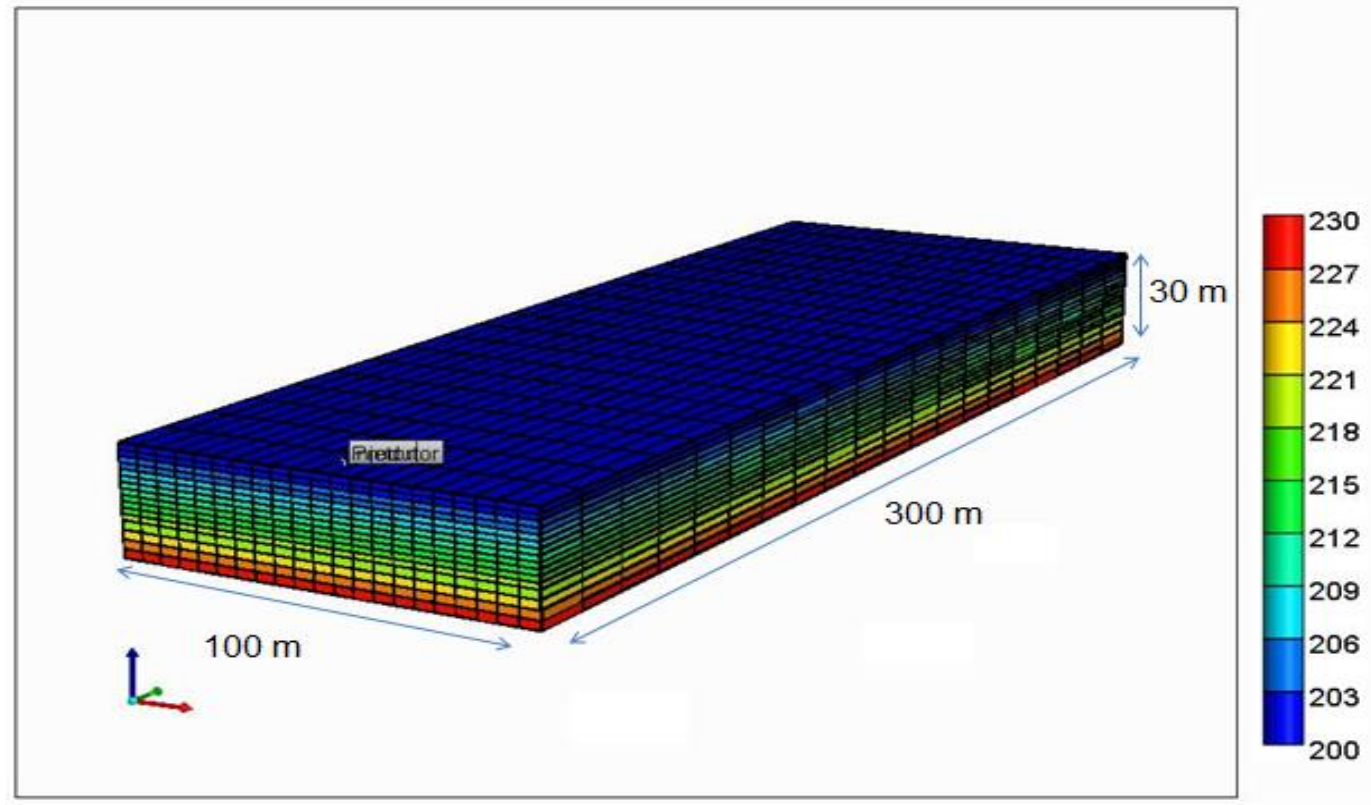

Figura 1 - Vista 3D do reservatório

O reservatório possui 300 metros de comprimento, 100 metros de largura e 30 metros espessura, foram perfurados dois poços horizontais paralelos um ao outro, sendo um de caráter injetor e outro produtor, localizados no meio do reservatório, no eixo x, para que o solvente se expanda simetricamente pelo reservatório. As completações possuem o mesmo comprimento do reservatório, $300 \mathrm{~m}$. O poço produtor foi completado na $11^{\mathrm{a}}$ camada, alguns metros acima da zona água, para não haver uma produção precoce da mesma, portanto o poço foi canhoneado apenas na zona de óleo. Já o poço injetor foi estudado em três casos diferentes, portando cada caso possuiu uma completação diferente, perfurado na $3^{\mathrm{a}}, 5^{\mathrm{a}}$ e $7^{\mathrm{a}}$ camada, respectivamente, para analisar a influência da distância vertical entre os poços, que podem ser observados na Figura 2. 


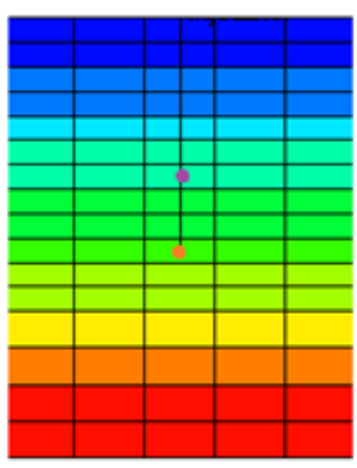

Distância Vertical $5 \mathrm{~m}$

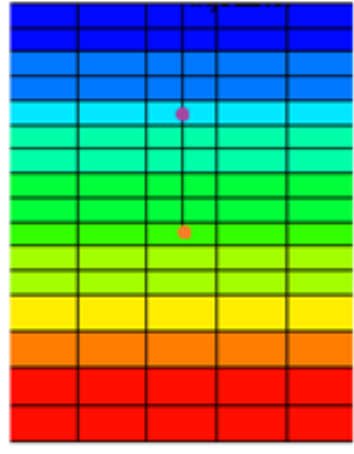

Distância Vertical $8 \mathrm{~m}$

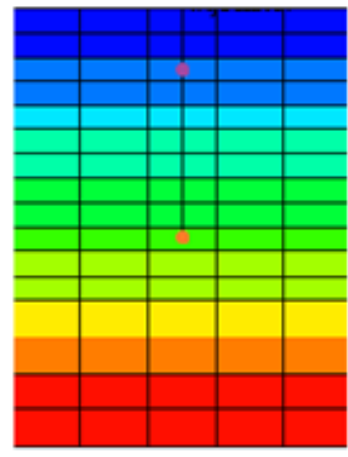

Distância Vertical $11 \mathrm{~m}$

- Poço Injetor

- Poço Produtor

Figura 2 - Configuração da completação dos poços

Para o estudo modelado, foram adotadas algumas condições operacionais. As simulações foram realizadas para representar a produção em um período de vinte anos. As Tabelas 3 e 4 estão descriminadas as condições operacionais dos poços, considerado como modelo base do sistema em estudo (sistema inicial) a tabela 3 e a tabela 4 as alterações dos parâmetros em estudo.

Tabela 3. Condições operacionais do poço injetor

\begin{tabular}{|c|c|}
\hline \multicolumn{2}{|c|}{ Poço Injetor } \\
\hline Pmax. (kPa) & Vazão de injeção $\left(\mathbf{m}^{\mathbf{3}} / \mathbf{d i a}\right)$ \\
\hline 3500 & 50 \\
\hline \multicolumn{2}{|c|}{ Poço Produtor } \\
\hline Pmin. (kPa) & Vazão máx de liquido (m³/dia) \\
\hline 196,5 & 200 \\
\hline Poços & Camada da Completação (Dist. Vert. $-\mathbf{8}$ m) \\
\hline Injetor & $5^{\text {a }}$ \\
\hline Produtor & $10^{\mathbf{a}}$ \\
\hline
\end{tabular}

Tabela 4. Intervalos dos parâmetros operacionais analisados

\begin{tabular}{|c|c|c|c|}
\hline & -1 & 0 & 1 \\
\hline Distância Vertical & $5 \mathrm{~m}$ & $8 \mathrm{~m}$ & $11 \mathrm{~m}$ \\
\hline Tipo de Solvente & $\mathrm{C} 5$ & - & $\mathrm{C} 7$ \\
\hline Vazão & $50 \mathrm{~m}^{3} / \mathrm{dia}$ & $100 \mathrm{~m}^{3} / \mathrm{dia}$ & $150 \mathrm{~m}^{3} / \mathrm{dia}$ \\
\hline
\end{tabular}

A influência dos parâmetros operacionais no fator de recuperação será analisada através do diagrama de Pareto e de gráficos. 


\section{RESULTADOS E DISCUSSÕES}

Foi realizado um estudo com três parâmetros operacionais, criando uma combinação entre eles para observar qual parâmetro apresentou melhor resultado no processo ao ser submetido a uma variação. Os parâmetros analisados foram o tipo de solvente injetado, a vazão de injeção e a distância vertical entre os poços produtor e injetor. A Tabela 5, contém 18 casos, com combinações diferentes dos parâmetros, e nela também apresenta o fator de recuperação da produção após 5 anos de injeção do solvente, apesar do projeto apresentar 20 anos de execução, mas por não haver discrepâncias entre os resultados ao passar dos anos foi escolhido apenas uma data para análise.

Tabela 5 - Fator de recuperação para os casos simulados

\begin{tabular}{|c|c|c|c|c|c|c|c|c|c|}
\hline & $\begin{array}{l}\text { Dist. } \\
\text { Vert. } \\
\text { (m) }\end{array}$ & Solvente & $\begin{array}{c}\text { Vazão } \\
\text { (m³/dia) }\end{array}$ & $\begin{array}{l}\text { FR } \\
(\%)\end{array}$ & & $\begin{array}{c}\text { Dist. } \\
\text { Vert. } \\
\text { (m) }\end{array}$ & Solvente & $\begin{array}{c}\text { Vazão } \\
\text { (m³/dia) }\end{array}$ & $\begin{array}{l}\text { FR } \\
(\%)\end{array}$ \\
\hline Caso 1 & 5 & $\mathrm{C} 5$ & 50 & 1,30 & Caso 10 & 8 & C7 & 50 & 3,09 \\
\hline Caso 2 & 5 & $\mathrm{C} 5$ & 100 & 0,83 & Caso 11 & 8 & $\mathrm{C7}$ & 100 & 3,16 \\
\hline Caso 3 & 5 & $\mathrm{C} 5$ & 150 & 1,14 & Caso 12 & 8 & $\mathrm{C7}$ & 150 & 2,89 \\
\hline Caso 4 & 5 & $\mathrm{C} 7$ & 50 & 1,76 & Caso 13 & 11 & $\mathrm{C} 5$ & 50 & 2,42 \\
\hline Caso 5 & 5 & $\mathrm{C} 7$ & 100 & 2,03 & Caso 14 & 11 & $\mathrm{C} 5$ & 100 & 3,55 \\
\hline Caso 6 & 5 & $\mathrm{C} 7$ & 150 & 1,73 & Caso 15 & 11 & $\mathrm{C} 5$ & 150 & 2,79 \\
\hline Caso 7 & 8 & $\mathrm{C} 5$ & 50 & 3,14 & Caso 16 & 11 & $\mathrm{C7}$ & 50 & 4,24 \\
\hline Caso 8 & 8 & $\mathrm{C} 5$ & 100 & 2,92 & Caso 17 & 11 & $\mathrm{C} 7$ & 100 & 4,33 \\
\hline Caso 9 & 8 & $\mathrm{C} 5$ & 150 & 3,24 & Caso 18 & $11 \mathrm{~m}$ & $\mathrm{C} 7$ & 150 & 3,97 \\
\hline
\end{tabular}

Para analisar a influência de cada parâmetro operacional e das interações foi utilizado o diagrama de Pareto, que está representado na Figura 3.

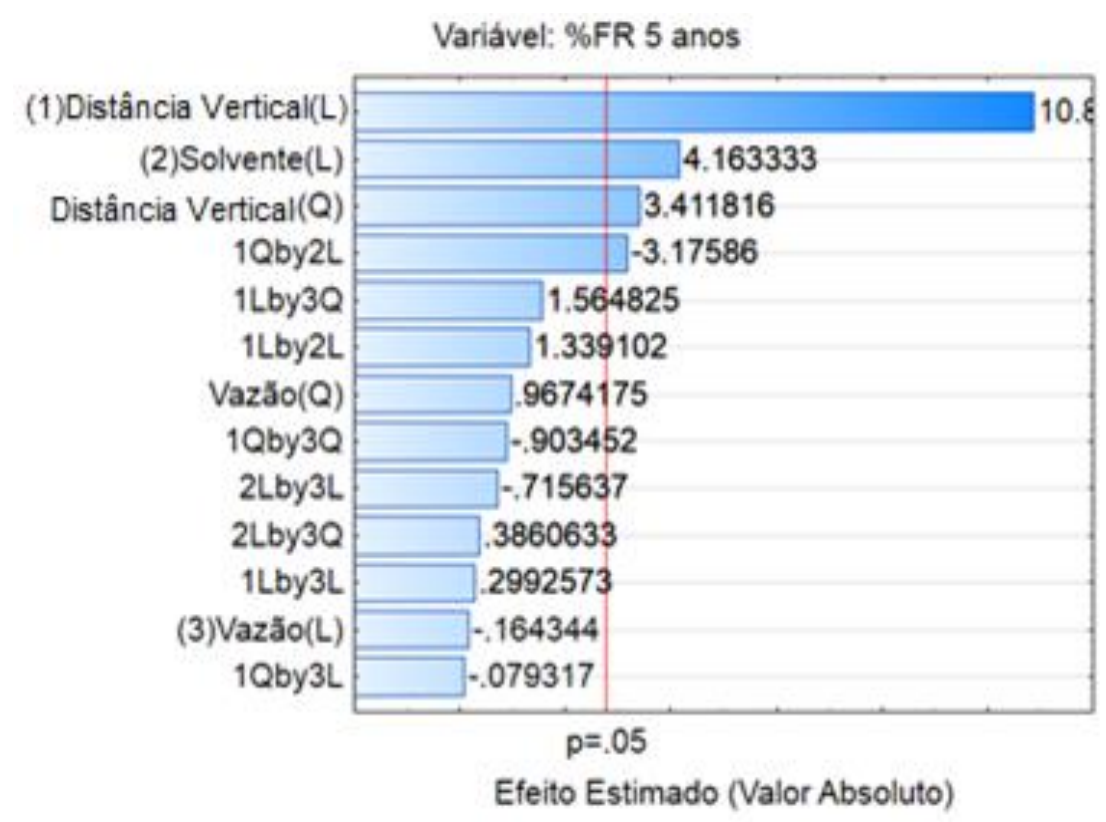

Figura 3 - Diagrama de Pareto das variáveis operacionais 
Na Figura 3, observa-se em ordem decrescente a relevância da influência de cada parâmetro individualmente, bem como a combinação entre eles. As variáveis que apresentaram maior influência foi a distância e o solvente, a vazão mostrou menor influência pois está do lado esquerdo da linha.

Na Figura 4 apresenta a superfície de resposta das variáveis: distância entre os poços e o tipo de solvente, que foram os parâmetros que mostrou mais influência, e a função objetivo estudada foi \%FR em 5 anos.

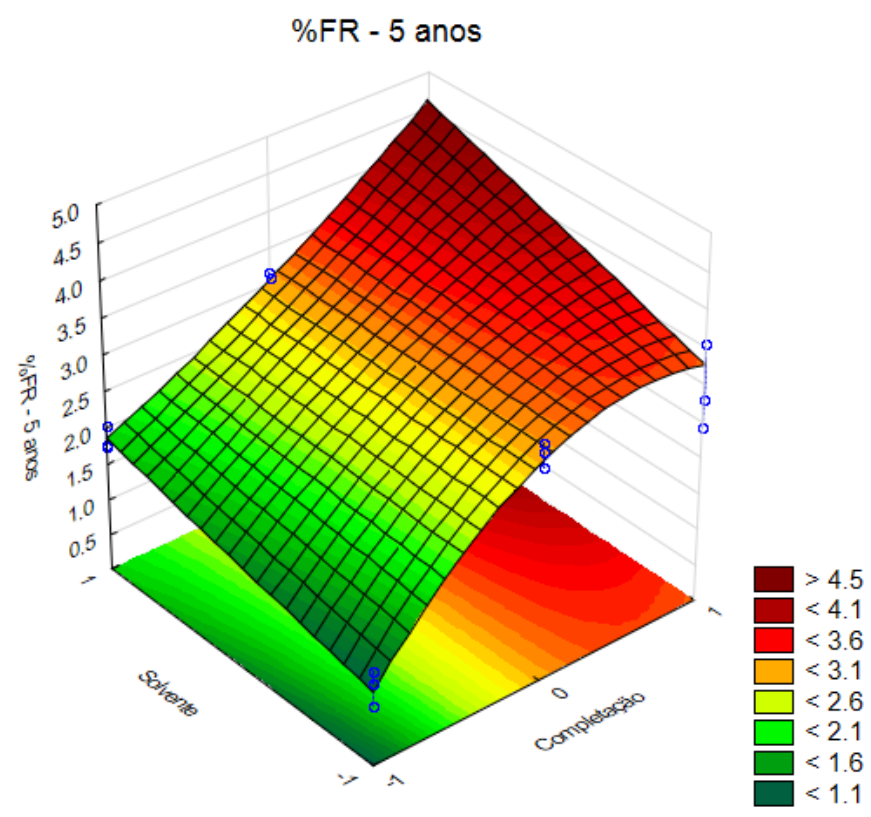

Figura 4 - Superfície de resposta dos parâmetros em estudo para 5 anos de produção

Na Figura 4, observa-se que quando os parâmetros tipo de solvente e distância vertical estão no nível máximo $(1,1)$, que correspondem ao solvente $\mathrm{C} 7$ e à distância de 11 $\mathrm{m}$, respectivamente, a recuperação do óleo é maior. Já quando diminui a distância vertical e utiliza o solvente C5 $(-1,-1)$ a recuperação de óleo é menor, isso ocorre devido a proximidade dos poços injetor e produtor que faz com que o solvente injetado seja produzido mais rapidamente não permitindo uma melhor expansão desse fluido no reservatório, diminuindo assim a área varrida. Já em relação ao tipo de solvente possivelmente o $\mathrm{C} 5$ possui menor miscibilidade em relação ao $\mathrm{C} 7$, obtendo assim menor produção.

Foi realizada a análise do tipo de solvente no período total do projeto, em 20 anos, com uma vazão de $50 \mathrm{~m} 3 /$ dia e uma distância vertical de $8 \mathrm{~m}$ no gráfico da produção acumulada de óleo versus tempo, assim como também foi feito o gráfico da produção acumulada de óleo para as diferentes distâncias verticais, cujos gráficos estão representados nas Figuras 5 e 6. 


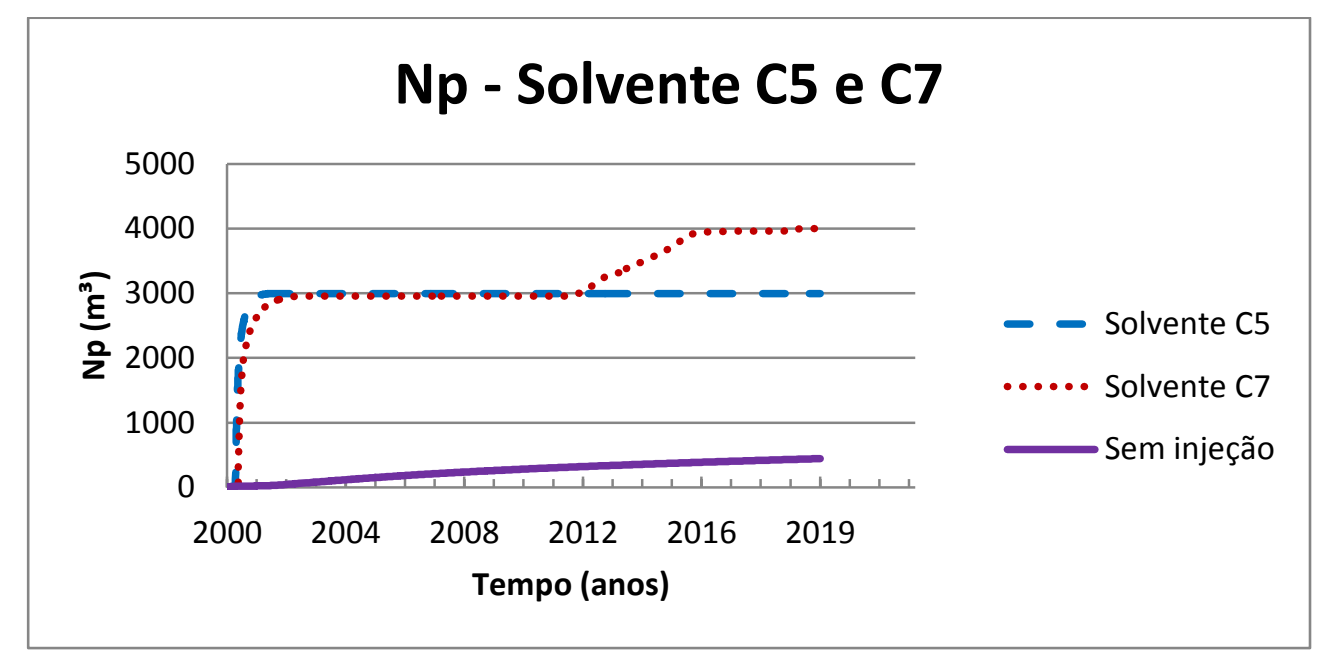

Figura 5 - Produção acumulada de óleo dos solventes C5 e C7

A partir da Figura 5 é possível ver que o reservatório possui uma recuperação primária extremamente baixa, isso devido a baixa energia de formação, cuja intensidade é determinada pelo volume e natureza dos fluidos que estão presentes no reservatório, como também dos níveis de temperatura e pressão. O óleo existente no reservatório possui uma viscosidade muito elevada, em torno de $10000 \mathrm{cp}$ o que dificulta muito seu deslocamento até o poço produtor. Ao injetar o solvente no reservatório, por ele ser miscível ao óleo ele se diluirá nesta fase reduzindo assim as tensões interfaciais e consequentemente a viscosidade, melhorando assim a fluidez do óleo. Como pode-se perceber que há uma diferença na produção de $1000 \mathrm{~m}^{3}$ do solvente $\mathrm{C} 7$ para o $\mathrm{C} 5$, isso possivelmente pode ser ocorrido devido a melhor miscibilidade do $\mathrm{C} 7$ o que resultou em um melhor escoamento do óleo.

A Figura 6 mostra o gráfico da produção acumulada de óleo para as diferentes distâncias verticais, utilizando o solvente $\mathrm{C}$, que obteve melhor desempenho no processo.

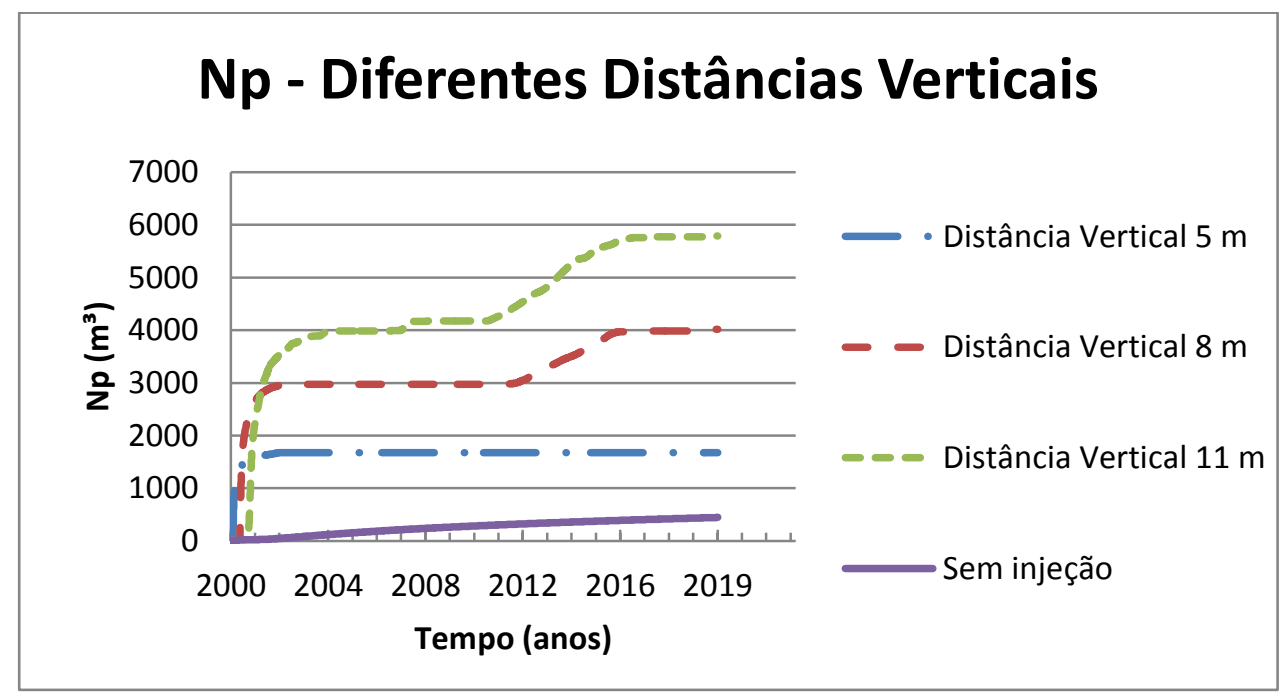

Figura 6 - Produção acumulada de óleo para as diferentes distâncias verticais 
Observando a Figura 6 é perceptível que o poço obteve uma melhor produção para uma distância vertical maior, isto se deve ao fato de que quanto maior a distância vertical entre o poço injetor e o poço produtor maior será a câmara do solvente injetado, consequentemente a área varrida do reservatório também será maior, consequentemente, terá um volume de óleo produzido superior. Portando nesse estudo foi obtida uma melhor recuperação do óleo com a utilização da injeção do solvente C7 ao poço injetor com uma distância vertical de $11 \mathrm{~m}$ do poço produtor.

\section{CONCLUSÕES}

A partir dos resultados pode-se aferir que:

O método VAPEX apresentou um incremento na produção de óleo. A injeção de solvente no poço contribuiu para um melhor escoamento do óleo dentro do reservatório, possibilitando uma maior recuperação, porém por se tratar de um óleo muito pesado não apresentou retornos significativos, pois o método tem um custo elevado e esse incremento pode não compensar sua utilização, do ponto de vista econômico.

* A seleção do tipo solvente e a distância vertical foram os parâmetros que mostraram maiores efeitos, principalmente a distância vertical, dentre os casos analisados a melhor distância foi de $11 \mathrm{~m}$, quanto maior a distância vertical maior a produção, e o solvente que apresentou maior produção foi o C7.

* A alteração na vazão de injeção não apresentou impactos relativos na produção, segundo o diagrama de Pareto.

\section{AGRADECIMENTOS}

À CMG (Computer Modelling Group) pelo simulador e ao PRH-PB 221 da Petrobrás pelo apoio financeiro.

\section{REFERÊNCIAS}

LIMA, D. M. S. B. - Estudo Paramétrico do Processo de Injeção de Solventes em Poços Horizontais para Reservatórios de Óleo Pesado. Dissertação de Mestrado em Ciência e Engenharia de Petróleo, Universidade Federal do Rio Grande do Norte, 2011.

BARILlAS, J, L, M.; Estudo da Recuperação de Óleo por Drenagem Gravitacional Assistida por Injeção de Vapor. Tese de Doutorado em Engenharia Química, Universidade Federal do Rio Grande do Norte, 2008.

GALVÃO, E. R. V. P. Injeção de Vapor e Solvente como um Método de Recuperação Avançada em Reservatórios de Óleo Pesados. Dissertação de Mestrado em Ciência e Engenharia de Petróleo, Universidade Federal do Rio Grande do Norte, 2008.

THOMAS, J. E. et al. Fundamentos da Engenharia de Petróleo. 2. ed.Rio de Janeiro: Interciência, 2001.

CAMPOS, L. O. Injeção de Vapor e Solvente em Reservatório do Nordeste Brasileiro - Trabalho de Conclusão de Curso, Departamento de Engenharia de Petróleo, Universidade do Rio Grande do Norte, 2013. 